\title{
RESPOSTA FISIOLÓGICA DE PLANTAS DE MAMOEIRO SUBMETIDAS AO DÉFICIT HÍDRICO
}

\author{
SILVA, Raimundo Thiago Lima da ${ }^{1}$ \\ OLIVEIRA NETO, Cândido Ferreira de ${ }^{2}$ \\ BARBOSA, Roberto Rivelino do Nascimento ${ }^{3}$ \\ COSTA, Roberto Cezar Lobo da ${ }^{4}$ \\ CONCEIÇÃO, Heraclito Eugenio Oliveira $\mathrm{da}^{5}$
}

ISSUE DOI: $10.3738 / 1982.2278 .779$

RESUMO: No Brasil, em especial no Norte, o mamoeiro tem sido tradicionalmente cultivado em condições de agricultura de sequeiro, sujeita aos elevados riscos causados pelas variações do clima. Objetivando-se avaliar o efeito do estresse hídrico sobre conteúdo relativo de água foliar e nos teores de sacarose, carboidratos, prolina e glicinabetaína nas folhas e raízes de mamoeiro (Carica papaya L), conduziu-se um experimento em casa de vegetação em delineamento experimental inteiramente casualizado, com dois tratamentos [irrigado (controle) e déficit hídrico], com 28 unidades experimentais, no qual cada unidade foi composta de uma planta/vaso. Os efeitos provocados pelo déficit hídrico, em plantas de mamoeiro, foi à redução do o conteúdo hídrico nas folhas e aumento nos teores de sacarose, carboidratos solúveis totais, prolina e glicina-betaína, tanto nas raízes quanto nas folhas.

Palavras-chave: Carica papaya L. Folha. Raiz.

\section{PHYSIOLOGICAL RESPONSE OF PAPAYA PLANTS SUBMITTED TO WATER DEFICIT}

SUMMARY: In Brazil, especially in the North, the papaya tree has traditionally been grown in conditions of rainfed agriculture, subject to high risks caused by climate variations. With the objective of evaluate the effect of water stress on leaf relative water content relative water content in leaves and sucrose contents, carbohydrates, proline and glycine-betaine in leaves and roots of papaya tree (Carica papaya L), an experiment was conducted in a greenhouse in a randomized experimental design, with two treatments [irrigated (control) and water deficit], with 28 experimental units, in which each unit was composed of a plant / pot. The effects of water deficit in papaya plants was the reduction of water content in leaves and increased levels of sucrose, total soluble carbohydrates, proline and glycine-betaine in the roots and leaves.

Keywords: Carica papaya L. Leaf. Root.

\section{INTRODUÇÃO}

O mamoeiro pertence à classe Dicotyledoneae, subclasse archichlamydeae, ordem Violales, subordem Caricineae, família Caricaceae e gênero Carica. A família Caricaceae consiste de 31 espécies agrupadas em quatro gêneros, dos quais três são americanos e um é africano. O gênero Carica é o único com espécies domesticadas, e entre essas o mamoeiro (Carica papaya L), é o mais importante comercialmente.

A importância da água para o mamoeiro relaciona-se tanto à falta quanto ao excesso. A restrição hídrica, além de reduzir o crescimento da planta, favorece a produção de flores masculinas e estéreis,

\footnotetext{
${ }^{1}$ Eng. Agrônomo formado pela Universidade Federal Rural da Amazônia, Mestre em Engenharia Agrícola pela Universidade Federal de Santa Maria e Doutorando em Agronomia - Fitotecnia pela Universidade Federal do Ceará

${ }^{2}$ Eng. Agrônomo, Msc e Dr. em Agronomia, Professor Adjunto da Universidade Federal Rural da Amazônia

${ }^{3}$ Graduando em Agronomia

${ }^{4}$ Graduado em Ciências Biológicas, Msc em Ciências Agrárias e Doutor em Bioquímica

${ }^{5}$ Eng. Agrônomo, Msc em Ciências Agrárias e Doutor em Agronomia - Fitotecnia
} 
reduzindo a produção de frutos. Por outro lado, o excesso de água na região em torno da raiz da planta diminui a aeração e afeta a absorção de nutrientes, aumenta o aparecimento de doenças, além de possibilitar a lixiviação dos nutrientes (MARIN et al., 1995).

A deficiência hídrica, então, afeta praticamente todos os aspectos do crescimento das plantas, como a anatomia, a fisiologia e a bioquímica. A fotossíntese, por exemplo, é severamente afetada pela diminuição de área foliar, pelo fechamento estomático e também pelos danos no aparelho fotossintético (TAIZ; ZEIGER, 2004).

Além desses efeitos, a falta de água por um período prolongado aumenta a suscetibilidade aos ataques de patógenos e pragas, porém diminui a suscetibilidade a organismos que requerem superfícies foliares úmidas ou solo úmido para infecção (BENINCASA; LEITE, 2002).

A sacarose faz parte de uma integração do crescimento e do mecanismo de aquisição e alocação de carbono entre diferentes órgãos das plantas (FOYER; PARRY; NOCTOR, 2003). A glicina betaína é requerida para proteger a planta, mantendo o contrapeso da água entre a célula vegetal e o ambiente (RONTEIN; BASSET; HASSON, 2002).

Os carboidratos encontrados nas folhas são alterados em quantidade e qualidade durante o estresse hídrico (CHAVES; OLIVEIRA, 2004) e podem agir como sinal em resposta ao estresse (CHAVES; MAROCO; PEREIRA 2003). A função de sinalizadores dos açúcares pode ser adaptativas osmoregulação (LAWLOR; CORNIC, 2002), mas ainda não está totalmente esclarecida (CHAVES; OLIVEIRA, 2004).

A prolina além do papel de ajustador osmótico, proporciona aos tecidos vegetais osmoticamente estressados as seguintes funções: integridade e proteção da membrana, dissipador ou redutor de energia, fonte de carbono e nitrogênio e eliminador de radicais hidroxil (MENESES et al., 2006).

Com o conhecimento dos mecanismos de ação do déficit hídrico associado com aqueles que podem conferir tolerância ao mamoeiro, será possível estabelecer estratégias de manejo do solo e da planta; tais como seleção de clones mais tolerantes; necessárias para que a cultura possa apresentar produções compatíveis com uma exploração sustentável. Além disso, o acervo de conhecimentos básico gerado servirá para o manejo de outras espécies cultivadas em condições ambientais semelhantes. O objetivo deste trabalho foi verificar o conteúdo relativo de água e os teores de sacarose, carboidratos, prolina e de glicina-betaína, em plantas de mamoeiro submetidas à deficiência hídrica.

\section{MATERIAL E MÉTODOS}

O experimento foi conduzido em casa de vegetação na Universidade Federal Rural da Amazônia (UFRA) - Campus de Capitão Poço, no município de Capitão Poço localizada na microrregião do Guamá no Estado do Pará, com latitude de 01²41"36' S e longitude 04706"39' W e altitude média da área em torno de $73 \mathrm{~m}$. O clima da região, segundo a classificação de Köppen, é do tipo Am com precipitação anual em torno de $2.500 \mathrm{~mm}$, com uma curta estação seca entre setembro e novembro (precipitação mensal em torno de $60 \mathrm{~mm}$ ), temperatura média de $26^{\circ} \mathrm{C}$ e umidade relativa do ar entre $75 \%$ e $89 \%$ nos meses com menor e maior precipitação, respectivamente (SCHWART, 2007).

Foram utilizadas mudas de mamoeiro aclimatadas em casa de vegetação por um mês. $\mathrm{O}$ experimento foi realizado no mês de junho de 2010, no qual as mudas foram submetidas a dois regimes hídricos [irrigado (controle) e déficit hídrico], no qual a simulação do déficit hídrico ocorreu pela suspensão da irrigação no período de 20 dias, o manejo da irrigação foi realizado de forma manual, por meio de um regador, com capacidade de 10 litros de água.

Nucleus, v.9, n.2, out.2012 
O delineamento experimental utilizado foi o inteiramente casualizado, com dois regimes hídricos (duas condições hídricas: controle e déficit hídrico), com 14 repetições, totalizando 28 unidades experimentais, no qual cada unidade foi composta de uma planta/vaso.

O conteúdo relativo de água e as concentrações de carboidratos solúveis totais, sacarose, prolina e Glicina-Betaína, foram realizadas pelos dos métodos de Slavick (1974); Dubois et al. (1956); Van Handel (1968); Bates; Waldren; Teare (1973); Grieve; Grattan (1983); respectivamente.

Os dados foram submetidos à análise de variância e às médias comparadas pelo teste de Tukey ao nível de 5\% de probabilidade de erro, por meio do software Sas- institute (1996).

\section{RESULTADOS E DISCUSSÃO}

O conteúdo relativo de água nas folhas das plantas controle e sob estresse hídrico foram $79 \%$ e $58 \%$, respectivamente (Figura 1). A análise estatística destes resultados indica que ocorreu redução significativa neste parâmetro após o estresse simulado.

Figura 1. Conteúdo relativo de água em plantas jovens de mamoeiro submetidas à suspensão hídrica durante 20 dias. As letras diferentes mostram significância estatística, em relação ao teste Tukey à 5\% de probabilidade. As barras representam os desvios padrões das médias.

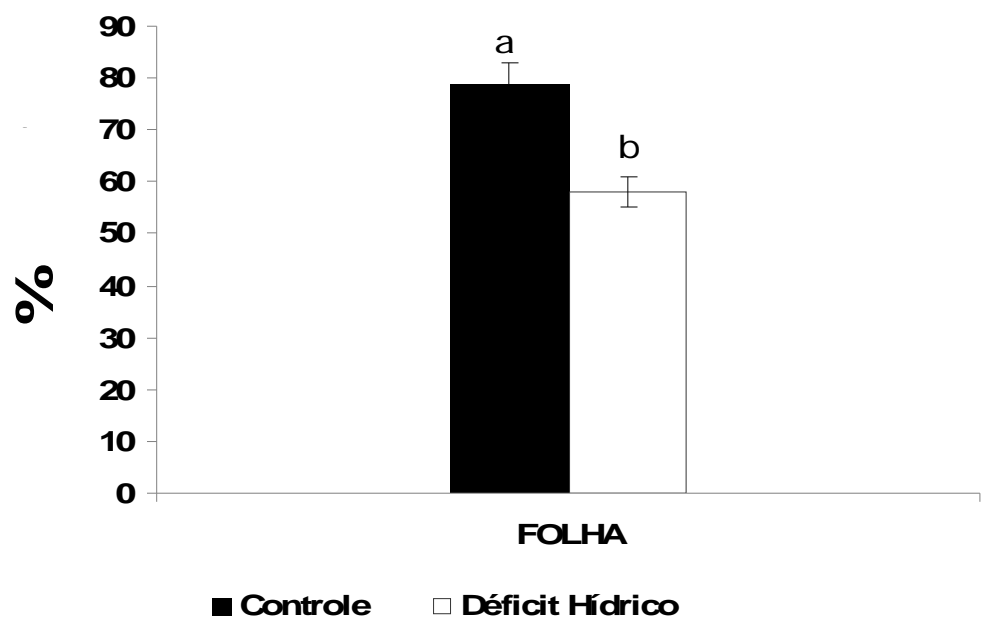

Fonte: Elaborado pelo Autor

A queda observada no conteúdo relativo de água é devido à menor taxa de absorção de água proveniente do solo pelo sistema radicial, e concomitante perda de água durante as trocas gasosas realizadas através dos estômatos (LOBATO et al., 2008). Esses resultados assemelharam-se aos encontrados por Queiroz; Gracia; Lemos Filho (2002) em trabalho realizado com aroeira, no qual foram obtidos valores maiores de conteúdo relativo de água em plantas irrigadas diariamente do que nas plantas estressadas por 14 dias.

As concentrações de sacarose na folha foram 16,98 e 24,45 $\mathrm{mg} \mathrm{g} \mathrm{MS}^{-1}$ nos tratamentos controle e déficit hídrico, respectivamente (Figura 2). Na raiz foram observados nas plantas controle e déficit hídrico as concentrações de 5,87 e 9,67 $\mathrm{mg} \mathrm{g} \mathrm{MS}^{-1}$, respectivamente. 
Figura 2. Concentrações de sacarose em raízes e folhas de plantas jovens de mamoeiro submetidas à suspensão hídrica durante 20 dias . As letras diferentes mostram significância estatística, comparadas pelo teste Tukey à 5\% de probabilidade. As barras representam os desvios padrões das médias.

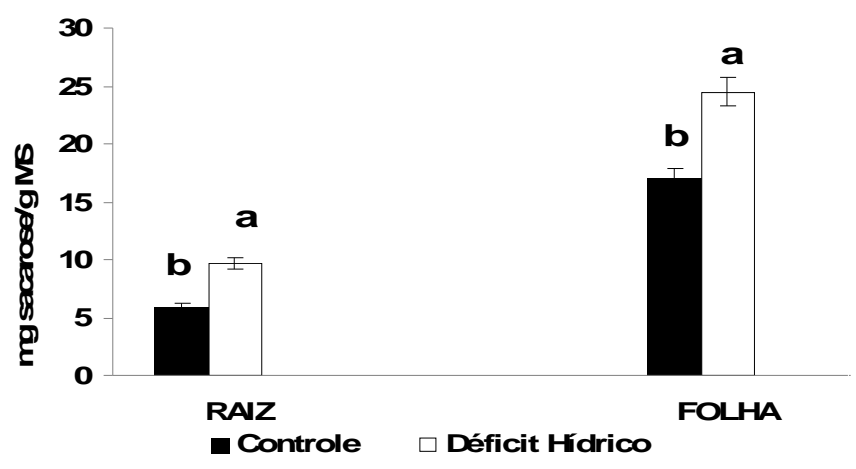

Fonte: Elaborado pelo Autor

Esses resultados deixam claro que a concentração de sacarose na folha é superior a quantidade encontrada nas raízes, assim como o déficit hídrico promove o acúmulo deste carboidrato. $\mathrm{O}$ aumento das concentrações de açúcares resulta na maior parte da hidrólise do amido, que requer atividade de enzimas hidrolíticas. As plantas recuperadas do estresse e as sementes de muitas plantas superiores são bons exemplos para a ligação do acúmulo de hidratos de carbono (sacarose em particular) com a aquisição da tolerância ao estresse (HOEKSTRA; GOLOVINA; BUITINK, 2001).

Tem sido observada em diversos estudos uma forte correlação entre o aumento na atividade das enzimas responsáveis pela hidrólise do amido e o acúmulo de açúcares em plantas submetidas à baixa disponibilidade de água. Quando polissacarídeos de reserva são mobilizados, o produto da hidrólise, frequentemente, é a sacarose, principal açúcar de transporte em plantas. Para que órgãos em crescimento (drenos) possam metabolizar essa sacarose, torna-se necessária sua degradação (MARTIM, 2003).

Os níveis de carboidratos solúveis totais na folha foram 4,05 e 11,21 $\mathrm{mmol} \mathrm{g} \mathrm{MS}^{-1}$ nos tratamentos controle e déficit hídrico, respectivamente (Figura 3). Na raiz foram observados nas plantas controle e déficit hídrico os teores de 2,71 e 4,48 mmol $\mathrm{g} \mathrm{MS}^{-1}$, respectivamente. Portanto, o comportamento relacionado ao aumento foi similar tanto na folha quanto na raiz, após o estresse estudado.

Figura 3. Concentrações de carboidratos solúveis totais em raízes e folhas de plantas jovens de mamoeiro submetidas à suspensão hídrica durante 20 dias. As letras diferentes mostram significância estatística, comparadas pelo teste Tukey à $5 \%$ de probabilidade. As barras representam os desvios padrões das médias.

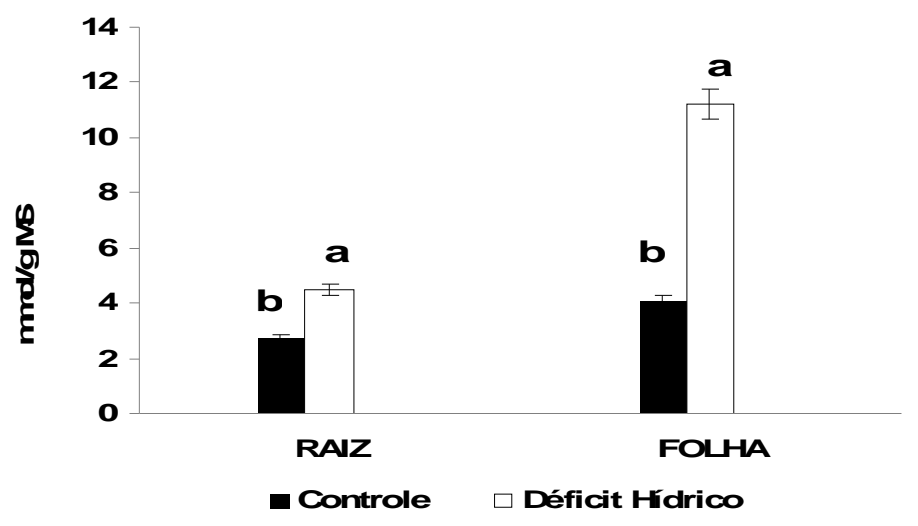

Fonte: Elaborado pelo Autor 
O aumento nos níveis de carboidratos solúveis totais está relacionado ao mecanismo de ajustamento osmótico da planta, visando maior retenção de água na célula pelo acúmulo de compostos orgânicos não tóxicos como os carboidratos solúveis totais. Resultados semelhantes foram obtidos por Oliveira (2005), trabalhando com quatro leguminosas arbóreas submetidas à deficiência hídrica, em que houve um incremento nas concentrações de carboidratos solúveis totais.

Os níveis de glicina-betaína na folha foram 21,2 e 29,2 $\mu \mathrm{g} \mathrm{g} \mathrm{MS}^{-1}$ nos tratamentos controle e déficit hídrico, respectivamente (Figura 4). Na raiz foram observados nas plantas controle e déficit hídrico os teores de 14,3 e 18,3 $\mathrm{mg} \mathrm{g} \mathrm{MS}^{-1}$, respectivamente.

Figura 4. Concentrações de glicina-betaína em raízes e folhas de plantas jovens de mamoeiro submetidas à suspensão hídrica durante 20 dias. As letras diferentes mostram significância estatística, comparadas pelo teste Tukey à $5 \%$ de probabilidade. As barras representam os desvios padrões das médias.

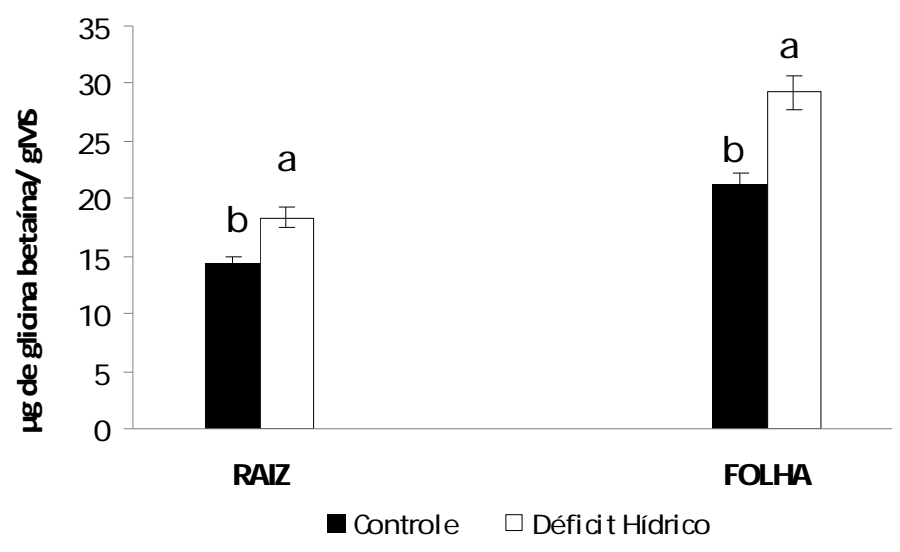

Fonte: Elaborado pelo Autor

Os resultados indicam que o comportamento é similar nas folhas e raízes, e caracterizado pelo acúmulo de glicina-betaína após o estresse simulado. O aumento nos níveis de glicina-betaína esta associado à função de ser um excelente ajustador osmótico em espécies vegetais, no qual ocorre uma sinalização particular e consequente aumento na síntese deste aminoácido.

Muitos trabalhos postulam que o aumento na concentração de solutos orgânicos em tecidos de plantas expostas ao deficit hídrico produz um ajustamento osmótico e reduz a desidratação celular, com preservação de estruturas celulares (VALLIYODAN; NGUYEN, 2006; SILVA et al., 2009).

Aumento nas concentrações de glicina-betaína em plantas sob deficiência hídrica, provavelmente, está associado a uma melhor absorção e transporte de água do solo para a parte aérea por meio de ajustamento osmótico, além de uma maior proteção da membrana celular, bem como proteção contra o mecanismo do estresse oxidativo das plantas (ASHRAF; HARIS, 2004).

Sendo assim, esse acúmulo ocorreu para proteger o metabolismo vegetal, uma vez que glicinabetaína pode atuar como osmólito compatível e mantendo o contrapeso da água entre a célula vegetal e o ambiente, estabilizando as macromoléculas (MELONI et al., 2004). (CARLIN; SANTOS, 2009) obteve resultados semelhantes em plantas jovens de cana-de-açucar (Saccharum spp., Poaceae), em que observou-se um acréscimo de glicina-betaína sob deficiência hídrica.

As concentrações de prolina na folha foram 5,18 e 12,91 $\mu$ mol $\mathrm{g} \mathrm{MS}^{-1}$ e na raiz foram 2,23 e 8,43 $\mu \mathrm{mol} \mathrm{g} \mathrm{MS}^{-1}$ nos tratamentos controle e déficit hídrico, respectivamente (Figura 5). As concentrações de prolina nas raízes e folhas aumentaram significativamente, nas plantas sob deficiência hídrica. 
Figura 5. Concentrações de prolina em raízes e folhas de plantas jovens de mamoeiro submetidas à suspensão hídrica durante 20 dias. As letras diferentes mostram significância estatística, comparadas pelo teste Tukey à 5\% de probabilidade. As barras representam os desvios padrões das médias.

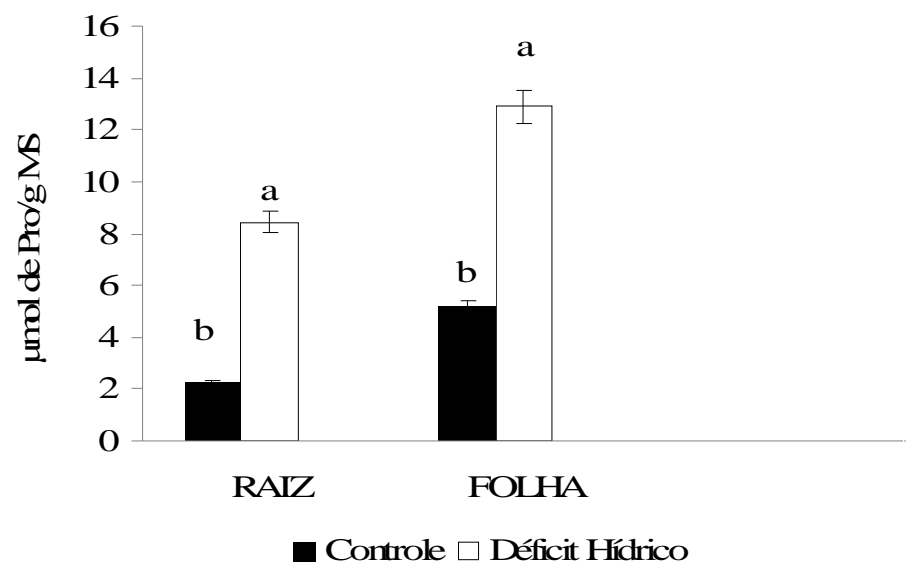

Fonte: Elaborado pelo Autor

Nas plantas sob deficiência hídrica, o aumento dos teores de prolina pode está relacionado ao aumento da atividade das enzimas proteolíticas promovendo uma disponibilidade maior desse aminoácido livre, no sentido de proteger os tecidos vegetais contra esse estresse, por servirem como reserva de nitrogênio, osmo-soluto e protetor hidrofóbico de enzimas e estruturas celulares.

Resultados semelhantes foram observados por (MAIA et al., 2007) em duas cultivares de milho e por Carvalho (2005) em plantas de paricá e guapuruvu submetidas a dois ciclos de deficiência hídrica.

\section{CONCLUSÃO}

O estudo revelou que o déficit hídrico de 20 dias em plantas de mamoeiro promoveu queda no conteúdo relativo de água nas folhas e aumento nas concentrações de sacarose, carboidratos solúveis totais, prolina e glicina-betaína, tanto nas raízes quanto nas folhas.

\section{REFERÊNCIAS}

ASHRAF, M.; HARIS, P. J. Potential biochemical indicators of salinity tolerance in plants. Plant Science, London, v. 166, n.1, p.3-16, 2004.

BATES, L. S.; WALDREN, R. P. E.; TEARE, I. D. Rapid determination of free proline for water-stress studies. Short communication. Plant and Soil, Dordrecht, v.39, n.1, p.205-207, 1973.

BENINCASA, M. M. P.; LEITE, I. C. Fisiologia Vegetal. Jaboticabal: Funep, 2002. 168p.

CARLIN, S. D.; SANTOS, D. M. M. Indicadores fisiológicos da interação entre déficit hídrico e acidez do solo em cana-de-açúcar. Pesquisa Agropecuária Brasileira, Brasília, v.44, n.9, p.1106-1113, 2009.

CARVALHO, C. J. R. Respostas de plantas de Schizolobium amazonicum [S. parahyba var. amazonicum] e Schizolobium parahyba [Schizolobium parahybum] à deficiência hídrica. Revista Árvore, Viçosa, v.29, n.6, p.907-914, 2005.

CHAVES, M. M.; MAROCO, J.; PEREIRA, J. S. Understanding plant responses to drought -from genes to the whole plant. Functional plant Biology, Victoria, v.30, n.2, p.239-264, 2003.

Nucleus, v.9, n.2, out.2012 
CHAVES, M. M.; OLIVEIRA, M. M. Mechanisms underlying plant resilience to water deficits: prospects for water-saving agriculture. Journal of experimental Botany, London, v.55, n.407, p.2365-2384, 2004.

DUBOIS, M.et al. Colorimetric method for determination of sugars and related substances. Analitical Chemistry, Washington, v.28, n.3, p.350-356, 1956.

FOYER, C. H.; PARRY, M.; NOCTOR, G. Markers and signals associated with nitrogen assimilation in higher plants. Journal of Experimental Botany, London, v.54, n.382, p.585-93, 2003.

GRIEVE, C. M.; GRATTAN, S. R. Rapid assay for determination of water soluble quaternary ammonium compounds. Plant and Soil, The Hague, v.70, p.303-307, 1983.

HOEKSTRA, F.A.; GOLOVINA, E.A.; BUITINK, J. Mechanisms of plant desiccation tolerance. Trends in Plant Science, London, v.6, n.9, p. 431-438, 2001.

LAWLOR, D.W.; CORNIC, G. Photosynthetic carbon assimilation and associated metabolism in relation to water deficits in higher plants. Plant Cell and Environment, Hoboken, v.25, n.2, p.275-294, 2002.

LOBATO, A. K. S. et al. Physiological and biochemical behavior in soybean (Glycine max cv. Sambaiba) plants under water deficit. Australian Journal of Crop Science, Austrália, v.2, n.1, p.25-32, 2008.

MAIA, P. S. P. et al. Conteúdo Relativo de Água, Teor de Prolina e Carboidratos Solúveis Totais em Folhas de Duas Cultivares de Milho submetidas a Estresse Hídrico. Revista Brasileira de Biociências, Porto Alegre, v.5, n.2, p.918-920, 2007.

MARIN, S. L. D.et al. Recomendações para a cultura do mamoeiro dos grupos Solo e Formosa no Estado do Espírito Santo. 4.ed. Vitória: EMCAPA, 1995. 57p. (Circular Técnica, 3).

MARTINS, D.et al. Caracterização química das plantas aquáticas coletadas no reservatório de Salto Grande (Americana). Planta Daninha, Viçosa, v.21, p.21-26, 2003. (Edição especial).

MELONI, D. A.et al. The effects of salt stress on growth, nitrate reduction and proline and glycinebetaine accumulation in Prosopis alba. Brazilian Journal of Plant Physiology, Londrina, v.16, n.1, p.39-46, 2004.

MENESES, C. H. S. G.et al. Aspectos genéticos e moleculares de plantas submetidas ao déficit hídrico. Revista brasileira de oleaginosas e fibrosas, Campina Grande, v.10, n.1/2, p.1039-1072, 2006.

OLIVEIRA, E. R. N. Respostas ao déficit hídrico de quatro leguminosas arbóreas, com uso potencial em sistemas de corte e trituração. 2009, 57f. Dissertação (Mestrado em Agronomia) - Universidade Federal Rural da Amazônia, Belém.

QUEIROZ, C. G. S.; GRACIA, Q. S.; LEMOS FILHO, J. P. Atividade fotossintética e peroxidação de lipídios de membrana em plantas de aroeira-do-sertão sob estresse hídrico e após reidratação. Brazilian Journal of Plant Physiology, Piracicaba, v.14, n.1, p. 59-63, 2002.

RONTEIN, D.; BASSET, G.; HANSON, A. D. Metabolic engineering of osmoprotectant accumulation in plants. Metabolic Engineering, v.4, n.1, p.49-56, 2002.

SAS INSTITUTE. SAS/STAT User's Guid: version 6.12, SAS Institute, Cary, NC. 1996.

SCHWART, G. Manejo sustentável de florestas secundárias: espécies potenciais no Nordeste do Pará, Brasil. Amazônia: Ciência; Desenvolvimento, Belém, v.3, n.5, p.125-147, 2007.

SLAVIK, B. Methods of studying plant water relations. New York, Springer-Verlag, 1974. 449p. 
SILVA, S. L. F.et al. Influência de porta-enxertos na resistência de mudas de cajueiro ao estresse salino. Pesquisa Agropecuária Brasileira, Brasília, v.44, n.4, p.361-367, 2009.

TAIZ, L; ZEIGER, E. Fisiologia vegetal. Porto Alegre: Artmed, 2004. 719p.

VALLIYODAN, B.; NGUYEN, H. T. Understanding regulatory networks and engineering for enhanced drought tolerance in plants. Current Opinion in Plant Biology, London, v.9, n.2, p.189-195, 2006.

VAN HANDEL, E. Direct microdetermination of sucrose. Anal Biochemical., v.22, n.2, p.280-283, 1968. 